\title{
O cronista Macedo e a formação do leitor no Brasil
}

\author{
Ana Cristina Coutinho Viegas ${ }^{1}$
}

Resumo: Este trabalho se propõe tecer considerações sobre a institucionalização do ensino da literatura brasileira e utiliza como corpus crônicas de Joaquim Manuel de Macedo reunidas no livro Um passeio pela cidade do Rio de Janeiro, publicado em 1862. O registro de medidas administrativas e pedagógicas estruturadoras da instituição constitui material de grande relevância para esse estudo.

Palavras-chave: Joaquim Manuel de Macedo. Crônicas. Ensino de literatura.

\section{Introdução}

Além da chegada tardia da imprensa, outra dificuldade para a difusão da cultura letrada em nosso país estava intimamente ligada à falta de uma política educacional que o dotasse de uma rede de ensino eficiente.

O Romantismo constitui um momento decisivo para a revitalização do pensamento e da cultura nacionais. Os ideais românticos de uma literatura genuinamente brasileira desaguaram na necessidade de formação de um público leitor. Entre nós, a história da literatura se confunde com a da imprensa. Com o objetivo de aumentar as vendas, os jornais, além de informar, precisavam entreter as pessoas. Ao abrir espaço para o folhetim, acabaram por protagonizar essa empreitada. Por outro lado, se a autonomia nacional passava pela cultura escrita, a maioria da população não tinha acesso aos livros, os quais circulavam apenas entre uma elite composta de estudantes e intelectuais.

\section{O cronista Macedo}

A partir dos anos 1840, com o desenvolvimento do romance, teve papel de destaque Joaquim Manuel de Macedo, cuja obra A moreninha se tornou o primeiro sucesso popular de nossas letras. Macedo se encontra entre os escritores românticos bastante preocupados em criar um público para a literatura brasileira. Tendo em vista o público da Corte, Macedo dosava cuidadosamente suas intervenções, o que pode ser observado, por exemplo, em seu

\footnotetext{
${ }^{1}$ Doutora em Teoria Literária pela UFRJ. Professora do Departamento de Língua Portuguesa e Literaturas do Colégio Pedro II desde 1997. Atualmente coordena a área de Português no Programa de Residência Docente na Pós-Graduação da mesma instituição de ensino. E-mail: anacristinaviegas@ @erra.com.br.
} 
livro Um passeio pela cidade do Rio de Janeiro, coletânea de crônicas publicadas no Jornal do Commercio. No capítulo dedicado à Igreja de S. Pedro, o cronista trata da corrupção e da impunidade a que estava submetida a cidade no século XVI, entretanto não deixa de fazer a seguinte ressalva: "Adivinho que vos achais fatigados, e que me íeis pedir para terminar aqui este passeio. Vou fazer-vos a vontade, anunciando-vos outro um pouco menos árido e um pouco mais divertido, na próxima sessão" (STRZODA, 2010, p. 358).

O mesmo livro se abre com um prólogo - "Aos meus leitores" -, em que o autor delineia o tipo de leitor da época:

(...) escrevendo eu também para o povo esta obra, cuja matéria é árida e fatigante, não quis expô-la ao risco de não ser lida pelo povo, que prefere os livros amenos e romanescos às obras graves e profundas.

Que fiz eu? Procurei amenizar a história, escrevendo-a com esse tom brincalhão e às vezes epigramático que, segundo dizem, não lhe assenta bem, mas de que o povo gosta; ajuntei à história verdadeira os tais ligeiros romances, tradições inaceitáveis e lendas inventadas para falar à imaginação e excitar a curiosidade do povo que lê, e que eu desejo que leia os meus Passeios; mas nem uma só vez deixei de declarar muito positivamente qual o ponto onde a invenção se mistura com a verdade.

Acertei ou errei, procedendo assim?

Decida o público, que é meu juiz ... (MACEDO, 1942, p. XVI).

José de Alencar também figura entre os escritores que demonstraram empenho na formação de um público para a literatura brasileira. No prólogo à primeira edição de Iracema, em 1865, Alencar faz um convite: “Abra então este livrinho, que lhe chega da corte imprevisto. Percorra suas páginas para desenfastiar o espírito das cousas graves que o trazem ocupado". E aconselha que a leitura seja feita "na varanda da casa rústica ou na fresca sombra do pomar, ao doce embalo da rede" (ALENCAR, 1958, p. 233). Na tentativa de seduzir e ampliar o reduzido grupo de leitores, evitavam-se os piparotes.

Macedo e seus contemporâneos lutaram contra a fragilidade de uma infraestrutura com poucas editoras, livrarias, bibliotecas e carente de um sistema escolar organizado. Além de ter-se consagrado como o primeiro romancista brasileiro, Macedo nos legou uma intensa produção como cronista, a qual ainda é pouco estudada. Foram quatro décadas de textos nos periódicos do século XIX. O livro de Michelle Strzoda, O Rio de Joaquim Manuel de Macedo: jornalismo e literatura no século XIX (2010) constitui uma pesquisa de fôlego no sentido de preencher essa lacuna. Somente no Jornal do Commercio, Macedo contou vinte e cinco anos de publicações ininterruptas. Além de publicar um grande número de textos na imprensa, dirigiu periódicos, como a Revista Guanabara, uma das primeiras publicações 
culturais de relevo no país. Fundada em 1849 por Macedo, Gonçalves Dias e Araújo PortoAlegre, permaneceu sob o comando do grupo até 1852.

O surgimento de revistas literárias foi um importante passo para a divulgação de textos que seguiam as preferências dos leitores do Império. Embora o público fosse essencialmente masculino, as mulheres não estavam excluídas:

[...] elas também liam e, portanto, consumiam as novidades literárias estampadas na imprensa, mas, em geral, acompanhadas por jovens rapazes um sobrinho ou primo da família dessas damas -, que anunciavam as palavras dos livros e dos folhetins da imprensa literária para as donzelas e senhoras da Corte. Macedo, Alencar e Nabuco, por exemplo, exerceram essa função de leitores para grupos de mulheres (STROZDA, 2010, p. 47).

Este trabalho se volta para o Macedo cronista e seu livro Um passeio pela cidade do Rio de Janeiro, publicado em 1862, mais especificamente para o capítulo dedicado ao "Imperial Colégio Pedro II”, instituição na qual o escritor atuou como professor de História do Brasil.

Cabem aqui algumas considerações sobre a crônica como gênero. De acordo com diferentes críticos, em seu sentido atual, constitui um gênero brasileiro pela originalidade com que aqui se desenvolveu. Ao longo de um percurso que vem da seção "Ao correr da pena", no Correio Mercantil, para a qual escrevia semanalmente José de Alencar, foi deixando de lado a intenção de informar e comentar - atribuída a outros textos que circulam na imprensa. Tornou-se mais leve, afastou-se da lógica argumentativa e penetrou no reino da poesia (CANDIDO, 1992).

Ainda no século XIX, o jornalista-escritor desejava se aproximar do leitor, e a crônica cumpria satisfatoriamente esse papel. Como afirma Antonio Candido,

[...] nelas parece não caber a sintaxe rebuscada, com inversões frequentes; nem o vocabulário 'opulento', como se dizia, para significar que era variado, modulando sinônimos e palavras tão raras quanto bem soantes. Num país como o Brasil, onde se costumava identificar superioridade intelectual e literária com grandiloquência e requinte gramatical, a crônica operou milagres de simplificação e naturalidade, que atingiram o ponto máximo nos nossos dias (CANDIDO, 1992, p. 16).

Mesmo tratando do trivial, a crônica deixa entrever a preocupação com grandes questões. No limite entre literatura e jornalismo, evita o espírito de reportagem, visto que, se, para o jornalista, o fato constitui um fim, para o cronista é apenas um meio. Muitas vezes, 
assume a forma de um breve ensaio, na medida em que aborda criticamente diversos temas, inclusive a própria literatura, propondo reflexões sobre o ato de escrever.

Se, por um lado, está ligada ao efêmero, por outro, tem o papel de preservar esse efêmero e pode até mesmo adquirir valor de documento de uma época. Na passagem do jornal para o livro, seu caráter circunstancial é amenizado, até mesmo porque aquelas que tendem ao envelhecimento não são incluídas nessas publicações. Há, porém, outras maneiras de analisála do ponto de vista histórico, já que, entre outros aspectos, o cronista recoloca para seus leitores a relação entre ficção e realidade.

Ao longo do século XX, correntes críticas se revezaram entre a valorização do estudo das relações entre o texto literário e o real e o destaque para as combinações linguísticas operadas no próprio texto (close reading). A partir de Mallarmé, a teoria da literatura constrói a concepção de autonomia da arte que acompanhará o Modernismo. De acordo com essa perspectiva, a arte cria sua própria realidade, ou seja, persegue-se uma barreira entre arte e cultura de massa, assim como entre linguagem literária e referência. Com o avanço das novas tecnologias, contudo, o debate em torno das relações entre ficção e realidade assumiu novos contornos, o caminho a ser trilhado pela teoria tornou-se mais complexo, com a necessidade não apenas de se rever o corpus que constitui seu objeto de estudo, mas também de se refletir sobre os métodos e pressupostos que orientam esse estudo.

Os avanços da mídia eletrônica alimentam uma sociedade do espetáculo em que, cada vez mais, ganha espaço o falar de si. Em contrapartida, percebe-se um movimento teórico voltado para a problematização do sujeito nessa sociedade e, no que nos interessa mais de perto, na literatura. Esse pensamento vem acompanhado por um olhar atento na direção de gêneros antes considerados "menores" - crônicas, diários e cartas - por permanecerem na fronteira entre o literário e o não-literário, apontarem mais diretamente para a chamada "realidade" e constituírem discursos relacionados com o "eu" que escreve.

Quanto ao leitor, o pacto que se estabelece tem um caráter de maior referencialidade do que em outros gêneros, como o romance. Mesmo assim, o cronista faz do seu texto um espaço para encenar uma subjetividade. Naquele espaço regularmente preenchido no jornal, constrói uma figura de autor que vai ganhando contornos de um cidadão comum, que mantém, em tom de conversa, certa intimidade com seu público.

É como imagens de um tempo consideradas como construções e não como dados que essas crônicas estão sendo aqui estudadas. Além disso, voltar-se para as crônicas de Joaquim Manuel de Macedo significa ampliar as possibilidades de procedimentos analíticos e expandir o feixe de relações culturais (SOUZA, 2002, p. 111), uma vez que esses textos colaboram 
para a reconstituição do ambiente literário e da vida intelectual do escritor e sua inserção no pensamento cultural de uma época.

\section{Um breve passeio pela história do ensino da literatura brasileira}

De acordo com Michelle Strozda, o Colégio Pedro II contava, até 1850, com uma equipe docente formada por nomes como o próprio Macedo, Gonçalves de Magalhães, Gonçalves Dias e Araújo Porto-Alegre, os quais frequentavam não só as salas de aula, mas também espaços de debate em torno das letras, como revistas, jornais, saraus literários e livrarias, produzindo literatura e promovendo cultura no cenário carioca (STRZODA, 2010, p. 34).

Os textos de Macedo sobre o Colégio estão agrupados em oito "passeios", que mesclam história, jornalismo, memória e literatura. O primeiro desses passeios se detém na origem da instituição:

Levar-vos-ei hoje ao Imperial Colégio Pedro II. Mas em vez de seguirmos já para a rua larga de S. Joaquim, onde existe o externato, ou para o Engenho Velho, onde se acha o internato deste importante estabelecimento, voltaremos ainda à rua de S. Pedro [...]. Este colégio foi fundado no dia 2 de dezembro de 1837. Certo é, porém, que a sua verdadeira origem data de um ano que não é possível bem determinar e que, no entanto, foi positivamente anterior ao de 1739 e posterior ao de 1733 [...] Essa bela instituição, de que hoje tanto nos ufanamos, é filha de humildes pais [...]. E o brilhante colégio que não se lembre de protestar contra estas verdades, negando esta sua procedência e sustentando que nunca teve parentesco com o seminário de S. Joaquim [...], entendeu o governo, digo, e entendeu bem, que era tempo de criar um grande colégio público de instrução secundária e resolveu, por decreto [...] converter o antigo seminário dos pobres órfãos de S. Joaquim em uma bela instituição daquele gênero, que digna e acertadamente denominou Imperial Colégio Pedro II (STRZODA, 2010, p. 383-403).

Um estudo desses textos revela, entre outros dados, o cenário educacional no Rio de Janeiro da época. No quarto passeio, ao descrever a inauguração do Colégio, Macedo destaca, por exemplo, a falta de livros apropriados para o estudo: "As aulas abriram-se no dia 2 de maio, notando-se algumas irregularidades, que foram pela maior parte devidas à falta de compêndios e livros apropriados para os estudos das diversas matérias" (STRZODA, 2010, p. 407).

Nesse mesmo passeio, enumera os decretos de 1837 a 1861 que regulamentaram a instituição, estabeleceram a grade disciplinar por séries, nomearam professores, enfim, apresenta um quadro da legislação e das principais deliberações do governo relativas à 
estruturação do Colégio. Mais uma vez, nota-se a preocupação do autor com seu público. Antes de um passeio tão árduo, previne:

Submeto-me, portanto à cruel necessidade de escrever um mal-arranjado índice da legislação do colégio. Quem não tiver coragem para acompanharme neste trabalho pode dar por terminado o passeio de hoje, e deixar-me só, navegando por este mare magnum (STRZODA, 2010, p. 408).

Mais adiante, entretanto, não deixa de apresentar uma justificativa para o detalhamento nas informações: "[...] é de regra absoluta que quem passeia não tem pressa e quem tem pressa não passeia" (STRZODA, 2010, p. 424).

O tom ameno empregado como estratégia para seduzir o leitor também não impede as críticas ao abordar, por exemplo, no último passeio, a baixa remuneração dos professores:

[...] o mais interessante é que, quando um professor deixa de dar aula, perde a gratificação correspondente ao dia em que faltou, e também perde a ajuda de custo. Somados, porém, estes dois prejuízos, ficam eles ainda muito aquém da despesa que se faz com a viagem. De modo que o professor ganha mais dinheiro não indo ao colégio do que ganha quando comparece nele, o que chegaria a fazer supor que o governo paga e excita os professores do Colégio Pedro II para não irem ao internato (STRZODA, 2010, p. 437).

Um pouco mais adiante, o cronista denuncia a morosidade do governo em providenciar a expansão do colégio para que mais meninos pudessem ser admitidos no internato:

A administração pública no Brasil, quando não caminha para trás, espanta pela sua morosidade. Se escapa de ter a natureza de caranguejo, não escapa de ter a natureza de preguiça [...] Em nome da mocidade estudiosa, eu peço ao governo que tenha mais atividade e mais zelo, e que se lembre das obras de que indispensavelmente carece o internato do Colégio Pedro II (STRZODA, 2010, p. 440).

Mesmo ao abordar temas mais espinhosos, Macedo se mantinha empenhado para que o leitor não largasse sua mão nessas caminhadas por cenários e instituições do Rio de Janeiro. Além do Colégio Pedro II, também fizeram parte do roteiro pontos da cidade como o convento de Santo Antonio e o Passeio Público.

No que se refere ao ensino da literatura, as crônicas de Macedo ajudam a esboçar um perfil da primeira metade do século XIX. No sexto passeio, por exemplo, encontramos uma homenagem ao corpo docente do Colégio. São citados professores de gramática portuguesa, 
latim e grego, entre outras disciplinas. Nota-se que o ensino de literatura brasileira ainda não fazia parte da grade curricular.

Em decreto de 1841, o plano de estudos elaborado pelo então reitor Joaquim Caetano da Silva dividia o curso em sete anos e o estudo da literatura se fazia presente no sexto e no sétimo anos, porém na perspectiva da retórica e da poética.

O decreto de 24 de outubro de 1857, além de dividir o colégio em externato e internato, apresenta novo plano de estudo que cria uma cadeira especial de História do Brasil. Também passa a integrar a grade curricular do sétimo ano a disciplina História da Literatura Portuguesa e Nacional.

Em seu livro Introdução à historiografia da literatura brasileira, o professor Roberto Acízelo de Souza (2007) apresenta um estudo do processo de institucionalização da literatura brasileira pela análise dos programas de ensino do século XIX, do Colégio Pedro II, estabelecimento fundado sob o patrocínio direto do imperador e destinado a servir de modelo para um sistema educacional a ser implantado no país. O Colégio Pedro II era uma instituição de ensino secundário, voltada à formação de bacharéis num período de sete anos. Como não havia no país curso superior de Letras - situação que persistiu até 1934 -, o colégio acabava preenchendo essa lacuna.

De acordo com o referido estudo de Roberto Acízelo de Souza, apenas em 1892 se consumou o processo de institucionalização da literatura brasileira no currículo escolar. $\mathrm{O}$ ensino literário passou a ser ministrado em uma única série, sendo representado exclusivamente pela disciplina História da Literatura Nacional. Além do próprio nome da disciplina e da presença amplamente majoritária no programa de tópicos da literatura brasileira, outro sinal de sua institucionalização era o livro adotado: História da literatura brasileira, de Sílvio Romero (SOUZA, 2007).

Contemporânea à fundação de instituições como o Instituto Histórico e Geográfico Brasileiro (IHBG), a inauguração do Colégio Pedro II integrou um projeto de formação de uma elite nacional. Concebido para ser o modelo de educação, seus programas deveriam servir de base para os outros colégios brasileiros. Sendo assim, estudar o processo de incorporação do ensino de literatura em seus planejamentos significa, por extensão, traçar um perfil dos estudos literários no país.

\section{Conclusão}


Ao dedicar um capítulo inteiro dos seus passeios ao Imperial Colégio Pedro II, Joaquim Manuel de Macedo o insere no cotidiano do Rio de Janeiro, juntamente com os jardins e as igrejas da cidade.

O último passeio se encerra com um alerta: "Lembre-se ao menos o governo de que este colégio se honra com o nome do Imperador, e de que o imperador o distingue e protege, e não perde uma única ocasião de manifestar o interesse que por ele toma" (STROZDA, 2010, p. 440). E um convite: "Outra vez aos carros, meus bons amigos! Voltemos de novo à cidade, onde nos esperam outros passeios [...]" (STROZDA, 2010, p. 440).

Macedo, incansável profissional das letras do seu tempo e precursor do nosso jornalismo cultural, publicou de forma sistemática na imprensa como escritor, articulista e cronista. No papel deste último, soube muito bem explorar a vocação desta cidade para a crônica.

O conjunto de crônicas estudado neste artigo ratifica, portanto, o empenho do autor na formação de leitores para nossa literatura e seu consequente interesse pela educação no país. As instituições escolares, por sua vez, responsáveis por eternizar livros como A moreninha, reivindicam seu papel de consagradoras, visto que, depois de um longo processo, canonizamse determinadas obras por sua inscrição nos programas didáticos. Constituindo um dos diversos segmentos culturais da esfera pública, a escola funciona como um dos agentes de conservação e, simultaneamente, dinamização do chamado cânone literário.

\section{Referências bibliográficas:}

ALENCAR, José de. Obra completa. Rio de Janeiro: Nova Aguilar, 1958.

CANDIDO, Antonio. A vida ao rés-do-chão. In: CANDIDO, Antonio et alii. A crônica: o gênero, sua fixação e suas transformações no Brasil. Campinas, SP: UNICAMP; Rio de Janeiro: Fundação Casa de Rui Barbosa, p.13-22, 1992.

MACEDO, Joaquim Manuel de. Um passeio pela cidade do Rio de Janeiro. Rio de Janeiro: Zélio Valverde, 1942.

SOUZA, Eneida Maria de. Crítica cult. Belo Horizonte: Editora UFMG, 2002.

SOUZA, Roberto Acízelo de. Introdução à historiografia da literatura brasileira. Rio de Janeiro: EdUERJ, 2007.

STRZODA, Michelle. O Rio de Joaquim Manuel de Macedo: jornalismo e literatura no século XIX. Rio de Janeiro: Casa da Palavra, 2010. 
Macedo as a chronicler and reader formation in Brazil

\begin{abstract}
This article aims at discussing the institutionalization of Brazilian literature teaching and draws upon the chronicles by Joaquim Manuel de Macedo from the book $U m$ passeio pela cidade do Rio de Janeiro, published in 1862. Registering the administrative and pedagogical measures which have structured the institution constitutes material of great relevance to this study.
\end{abstract}

Key words: Joaquim Manuel de Macedo. Chronicles. Literature teaching. 